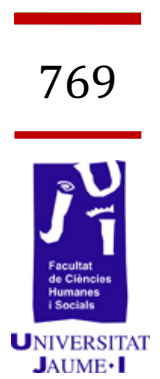

\title{
La experiencia ante la muerte en Cuatro noches romanas (2009), de Guillermo
} Carnero

Mã Isabel Tudón Martínez al111793@uji.es 
En el presente trabajo pretendemos indagar en los procesos que configuran la experiencia ante la muerte en Cuatro noches romanas (2009), de Guillermo Carnero; una meditatio mortis que el poeta realiza a partir de la reflexión en forma dialogada y alegórica con un imaginario personaje femenino, que se dibuja como la muerte, y al que acompaña durante cuatro noches, en la ciudad de Roma. Sirviéndose de un estilo poético que tiene sus raíces en la llamada estética veneciana -desarrollada por los poetas novisimos- el poeta utiliza, entre otros recursos, la metapoesía y el culturalismo como respuesta a su preocupación por una renovación del lenguaje poético y como una forma de tomar distancia ante un tema, tópico de la literatura, mediante la expresión indirecta de los sentimientos, evitando todo confesionalismo.

Palabras clave: Guillermo Carnero, poesía de la experiencia, diálogo, muerte, culturalismo, autoconocimiento, metapoesía, Roma.

\section{Introducción}

Este artículo es fruto del curso de doctorado "De los novísimos a la poesía de la experiencia (1970-2000)", impartido por el profesor Santiago Fortuño, en el que se estudiaba la evolución de la poesía desde unos planteamientos estéticos de renovación del lenguaje, de los poetas que rompían el compromiso moral con la realidad social, anterior a los años 70 del pasado siglo, a una poesía que se nutre de la experiencia personal como materia poética.

La elección del libro Cuatro noches romanas (2009), de Guillermo Carnero, obedece a que en él podemos apreciar la evolución que en estos últimos tiempos se ha producido en la poesía española, de manera especial en la renovación del lenguaje poético, y de indagación de nuevas formas de expresión poética. El libro, aparecido en plena madurez poética del autor, es el último libro de poesía de Guillermo Carnero, y el duodécimo en su trayectoria poética, y en él se desarrolla el tema de la experiencia ante la muerte.

En Guillermo Carnero, al igual que en muchos poetas de su generación, en los años ochenta, se produce una vuelta al intimismo, a la preocupación por la expresión de la emoción vivida. Sin dejar de trabajar los planteamientos novísimos, cuya principal preocupación sería el lenguaje y su esmero en la expresión verbal, el autor recrea de una manera original un tema clásico, el de la meditación ante la muerte. Su enfoque tiene la originalidad de expresar la vivencia de la caducidad de la vida y de cómo afrontar, aceptar y expresar la experiencia ante la muerte, a partir de un doble juego, el vivencial y el cultural, que envuelve esa experiencia; así, quedan imbricadas en su poema la realidad y la ficción, lo cultural y lo íntimo. 
Ambientado en la ciudad de Roma, el libro se impregna de todo el simbolismo que esta ciudad tiene (grandiosidad, belleza, eternidad), pero en la que también puede encontrarse la miseria o la tristeza de ciertos lugares. La Roma nocturna será, pues, el escenario donde se dramatice un diálogo íntimo con la muerte, una reflexión del poeta frente a su destino.

Guillermo Carnero, en este libro, ha creado una poesía intimista, que tiene como base la experiencia interiorizada, cargada de significado conceptual y cultural; además, concibe la escritura como autoconocimiento. ${ }^{1}$ y la razón de escribir, expresada en sus poéticas, es revelada como "una aventura de salvación personal" es decir, la comunicación de la experiencia lleva al autoconocimiento, y este a la salvación personal, porque, "la poesía, lo pretenda o no, da respuesta a preguntas relativas a lo más íntimo del ser humano"(2008: 266). De esta forma, los elementos descriptivos del proceso experiencial que construyen el poema, la forma, el estilo, los temas, están en función de ello. Nuestro objetivo consistirá en describir los sentimientos que afloran en el poema y su evolución, a partir de un análisis de los recursos poéticos empleados, de manera especial del culturalismo y la metapoesía, con los que el poeta vehicula dicha experiencia y dialoga con la tradición literaria; también interpretaremos este libro a la luz del conjunto de su obra poética, puesto que la obra de Carnero resulta "un todo orgánico", una unidad de sentido, como ha señalado Carlos Bousoño, "todos sus libros son en realidad uno", y él mismo confirma (2008: 41).

Cuatro noches romanas es, pues, la expresión dramatizada de un encuentro o "desencuentro", en tensión, con la muerte, (con su irracional visión) cuyo diálogo produce un ejercicio de autoconocimiento, articulado a partir de una intelectualización del sentimiento.

\section{La poesía como indagación en el autoconocimiento, las claves de la poética de Guillermo Carnero, en Cuatro noches romanas}

A la hora de diseñar la manera de acercarnos a este libro, hemos tenido en cuenta la poética del autor, la concepción y el papel que le otorga a la escritura poética, con el fin de orientarnos en describir los significados y la lectura de su poesía, como ya esbozábamos en la introducción. Así pues, y a pesar de que el propio autor considera que las poéticas son inútiles, que la teoría se olvida y lo que de verdad importa es la práctica, lo cierto es que Guillermo Carnero, a lo largo de su trayectoria como crítico literario y como poeta, ha expuesto sus ideas sobre poesía, sobre el proceso creativo, esto es, lo que él considera como principios básicos que dirigen su escritura poética y ha indagado en cómo se desarrolla dicho proceso, sus fuentes, sus técnicas, su filosofía; porque, como él dice, "con todo, es inevitable que un escritor haya llegado con el tiempo a ciertas ideas acerca de su propia escritura". "Estas ideas, que prodríamos llamar

\footnotetext{
${ }^{1}$ Como dice en su libro Poéticas y entrevistas... : "Yo diría que para mí la poesía es autoconocimiento, y que a ese autoconocimiento está subordinado cualquier conocimiento de lo otro."( 2008:270)
} 
"reflexiones de taller", son las que verdaderamente interesan, sin pretender que se conviertan en principios de validez universal". (2008: 97).

En concreto nos interesa saber lo que opina el autor sobre el hecho de escribir, así dirá: "la obra de un escritor está determinada por la necesidad que le impulsa a escribir y por la relación que mantiene con la tradición de su género literario y su lengua, y por otra, con la sociedad a la que pertenece".(2008: 97). En este sentido, lo que le lleva a escribir a Carnero es una vivencia de la realidad, un impulso, como en el caso de Cuatro noches romanas (2009), que bien pudiera ser el sentimiento de crisis, de reflexión de su propia trayectoria como escritor ${ }^{2}$. Así mismo, en cuanto a la relación que el poeta tiene con la tradición literaria, en la que desea continuar, la postura que tiene es clara y bien definida, al elegir él mismo formas de expresión que le ofrece dicha tradición, y que continuamente renueva; y por otro lado, en cuanto a la relación del poeta con la sociedad, dice que esta se muestra inexistente para él, pues el poeta ofrece una forma de conocimiento que es considerado un artículo de lujo que la sociedad ha dejado de requerir; por ello, la concepción que tiene de la poesía y de su finalidad será la de un objeto de conocimiento intelectual, para una minoría. El fin de la poesía, dirá el autor, "está en devolver dignidad y libertad al signo lingüístico, la función del lenguaje poético no es comunicativo, en exclusiva, pues "la comunicación presupone usar signos de significado unívoco, mediante los cuales el que escribe comunica su mensaje y el que lo lee lo descodifica como si fuera un trasvase de significados mente a mente". Por contra, para Carnero "el poema es un mensaje polisémico finito" (Carnero, 2008: 25), pues la actitud poética está teñida de afectividad, por lo tanto de subjetividad. Cuatro noches romanas, es un poema que ofrece una forma nueva, renueva el signo lingüístico, haciendo una lectura diferente de la tradición literaria. ${ }^{3}$

$Y$ respecto al proceso creador, lo describe a partir del momento tras el que una vivencia o una experiencia le han afectado emocionalmente:

Conocemos por los sentidos, pero para que las experiencias sensoriales signifiquen tenemos que aplazarlas en la conciencia y en la memoria; a cambio de esa conservación perdemos la inmediatez sensorial que nos aporta la ilusión de estar vivos. Cuando la vivencia se interioriza, se carga de significado conceptual y cultural; así que, la llamada realidad acaba siendo un espejismo, un fenómeno de percepción imaginaria, causada por lo que en él se oculta; la relación con la realidad y la conciencia de ella es lo que nos concede identidad".(Carnero, 2008: 247).

$Y$ en último término, para Guillermo Carnero la necesidad de conocerse, de saber quién es, es la única razón que lo lleva a escribir poesía, una especie de terapia: explicarse a sí mismo y recuperarse de esa herida emocional "La necesidad de saber quién soy es lo único que siempre me ha llevado a escribir", "La poesía es para mí una indagación en el

\footnotetext{
${ }^{2}$ Como dirá Carnero, "Cada vez que irrumpe la poesía en mi vida es porque me he visto obligado a tomar en cuenta una modificación de mi horizonte vital, emocional e intelectual a la vez." (2008: 2001)

3 Para Carnero, sería una poesía inmoral aquella que despreciar a su lector al ofrecerle obviedades y reiterarle lo que ya sabe, en lugar de inpulsarlo al descubrimiento y la sorpresa. (2008: 273)
}

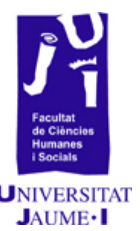


autoconocimiento", "Uno ha de curarse cuando ha sufrido una herida emocional que ha puesto en peligrio su equilibrio y ha obligado a reconsiderar su entidad personal. Mi experiencia es que el autoconocimiento que que la poesía conlleva supone el gran alivio de frenar esa crisis y en cierto modo neutralizarla." (2008: 245).

Guillermo Carnero, en Cuatro noches romanas, ha conjurado a los fantasmas para neutralizarlos, ha querido indagar en un sentimiento, que le angustia, no pasa de largo, para conocerse mejor. Como iremos desgranando, hará un recorrido por la experiencia y las vivencias pasadas e interiorizadas, sin huir del intimismo, pues "la poesía es pensamiento y lenguaje imantado de emoción", pero replanteado a través del culturalismo (no por evasión o simple superación del lenguaje) sino para hacerse entender mejor, para que no quede en un estado primario. Además, con esta técnica, se perpetua en la tradición. El paso siguiente en el complejo proceso, el intelectualismo, se manifiesta en la reflexión que se hace en el poema sobre la propia escritura, es decir, la metapoesía, que "da respuesta a interrogantes personales cargados de relevancia emocional" (2008: 55) al asumir esa reflexión con inteligencia emocional.

Los sentidos de lectura, que Cuatro noches romanas nos suscita, podremos hallarlos mejor si ajustamos su lectura a las claves que el propio poeta nos ofrece ${ }^{4}$ : un texto que adquiere formas de la tradición literaria, que comunica la experiencia intima, -ante la muerte- a través de claves culturales e intelectuales, para poder ser transmitida según los deseos del poeta, con el fin último de autoconocerse y reflexionar en ese conocimiento, en el sentido que tienen las palabras de Gil de Biedma cuando decía que "escribir poesía es una aventura de salvación personal". (2008: 99).

\title{
IV. Análisis de los elementos que configuran la experiencia ante la muerte en Cuatro noches romanas
}

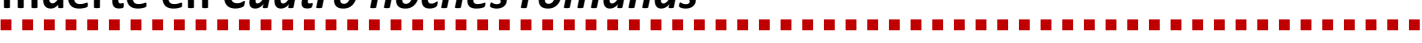

Una vez hemos aclarado algunos conceptos básicos referentes a la poesía, la experiencia y a los mecanismos del proceso creador en Guillermo Carnero, pasamos a identificar y analizar aquellos elementos que han formado la materia poética, las experiencias interiorizadas, los procedimientos estéticos que le han servido de código con el que comunicar dicha experiencia, así como también identificar las reflexiones en el texto que resultan de esa indagación en el autoconocimiento, fin último de toda escritura poética para el autor.

Todo ello viene a resumirse en lo que Carnero considera la fórmula que ha utilizado en cada uno de sus libros, intimismo, metapoesía y culturalismo. "Todos mis libros responden a esa fórmula. Puede variar la proporción de cada uno, pero no la fórmula" (Carnero, 2008:244).
\end{abstract}

\footnotetext{
${ }^{4}$ Aunque siempre queda la "catarsis" de leer un texto dramático, que presenta una moral poco convencional, sin pasar por este filtro interpretativo. Un texto lleno de imágenes sensoriales mezcladas con el discurso reflexivo, abstracto.
} 
Estos tres elementos, armónicamente incrustados en la trama del poema, son los materiales con los que dibuja una imagen, la de la experiencia ante la muerte. El producto resultante, el texto poético, se convierte en un artículo de difícil lectura, puesto que tenemos que hacer una constante búsqueda de significados a un lenguaje lleno de simbolismo y referencias culturales en los contenidos (una lectura paralela, múltiple). Nos centraremos en primer lugar en la arquitectura del poema, la forma y la disposición, el género, la relación de la estructura formal con el contenido. En segundo lugar estudiaremos los temas que aparecen a lo largo del poema, lugares comunes en la literatura, y cómo se reflejan en la experiencia del yo lírico, -y en su "interlocutor", produciendo una doble perspectiva. De este diálogo se puede deducir la evolución del sentimiento, que tiene su génesis en una vivencia íntima, y el cambio de actitud que se va operando en el poeta. Estudiaremos cómo se expresa en el texto.

Las imágenes que se generan en el poema acerca de la experiencia ante la muerte, hechas de incertidumbres, miedos, preguntas, reflexiones, dudas, interrogaciones ficticias a este personaje, se ofrecen mediante un código que podríamos llamar de intelectualización del sentimiento, y para ello recurre el autor a la combinación de recursos poéticos y discursivos, especialmente en el plano semántico de la lengua, (simbolismo, culturalismo, metapoesía, metáfora, imagen).

\subsection{Estructura del libro}

Cuatro noches romanas es un largo poema dialogado entre un personaje femenino, que tiene todos los atributos para representar la muerte, y un interlocutor, el yo poetico, que puede representar al poeta, pero no necesariamente. Está dividido el libro en cuatro partes, que se corresponden a las cuatro noches pasadas en la ciudad de Roma, cuatro encuentros entre ambos personajes.

Cada encuentro tiene un escenario diferente, con una carga simbólica y significativa cultural muy fuerte:

- Noche primera. Campo de Fiori.

- Noche segunda. Jardín de Villa Aldobrandini.

- Noche tercera. Cementerio Acatólico.

- Noche cuarta y albada.

Las cuatro partes se corresponden con las cuatro formas de enfrentar y asumir ese sentimiento de desolación frente a la idea de la muerte y la búsqueda de salvación. De estos encuentros se desprenden sentimientos de atracción, rechazo, repugnancia, seducción, rebeldía, aceptación...un tanto contradictorios. Además, la propia organización del poema describe una gradación de la experiencia y la clave de los posibles caminos de interpretación. Es decir, que la estructura del libro evoca la evolución del sentimiento del yo poético.

En esta meditada forma de expresión y organización del poema, toma relevancia, y le da un sentido introductorio, la cita inicial que aparece bajo el título de cada parte, versos de reconocidos poetas románticos: Jhon Donne, Hölderlin, Leopardi, Shelley. Son una sugerente referencia cultural, que evoca en cada parte un lugar de la ciudad relacionado con la muerte; 
nos da pistas de cómo articula su íntma experiencia, de la significación que para él tiene, y lo quiere expresar con el lugar sugerido; o por lo menos rodear la situación de un halo especial de sentimiento.

a) En la primera parte, Noche primera. Campo de Fiori, la presencia de esa "dama" se justifica como una búsqueda del poeta hacia ella. La razón de este encuentro buscado esta basado en la peticióm del poeta (a la muerte) para que, haciendo uso de sus atributos, le ayude a borrar y destruir sus recuerdos. Veámoslo en un extracto del diálogo, donde dice la dama, como una provocación:

- "Después de tantos años escribiéndome /hoy has venido a verme."

A lo que el poeta dirá:

- Siempre supe/ que hacia ti me llevaba mi destino..."

"a los cuerpos que duermen sosegados/ en el aplazamiento del deseo/

les oreas y alargas su delicia/ para que se aniquilen por inercia/ de su felicidad...

Y a esta especie de reproche responde la dama, aclarando su misión:

- "Mi juego y mi placer son sembrar el espacio/ de esos signos de muerte sucesiva..."

Por ello el poeta le ruega:

“...Sé que no te merezco/ todavía; te pido/ solo una señal: llueve/ sobre todas las flores, y deshójalas./ Arrastra todos mis recuerdos, que son manchas de sangre."

b) La Noche segunda se desarrolla en el Jardín de Villa Aldobrandini, lugar abandonado, en ruina, que recuerda a otras épocas; y a modo de guía y con ese conocimiento que le da el dominio del tiempo, dirá este personaje:

-“Nadie, hace siglos, viene por la noche/ a este lugar oscuro y solitario", a lo que contesta el poeta: “_Lo sé; pero me atrae su rüina/.../ la fuente muda cuya taza cubre un amasijo de raíces muertas./ hoy no quería verte/ entre las luces y el bullicio ..."

Una afirmación que llevará a la reflexión sobre la efímera belleza de las cosas, en un diálogo que ahonda en el tópico de la fugacidad de la vida y la inutilidad de la salvación por la belleza, como asevera esta misteriosa dama:

“De qué te serviría. La belleza/ no será nunca en ti; no la tendrás/ por mucho que la estreches..."

El poeta siempre ha sentido una atracción por el arte, en este caso un arte arquitectónico, encerrado, pero también por el espacio abierto, en la que el hombre ha moldeado la naturaleza, como son los jardines.

c) c)- La noche tercera romana se desarrolla en el cementerio Acatólico. Es una invitación al olvido, para evitar el dolor: Así interviene el poeta:

- "Un día me dijiste: tu peor enemigo/ es la memoria; aprende de los pájaros..."

Y la afirmación de la dama lleva a pensar en la belleza de la muerte en los cementerios:

"Mira a tu alrededor; no te complazcas/ solo en la destrucción y en la ruina. / No hay lugar en el mundo, donde brille/ más alta/ la belleza de la muerte." 
Sin embargo, ante una tumba, dirá que en esa aparente serenidad reposan personas que vivieron atormentadas; luego la enseñanza es que se trata de una belleza y una serenidad engañosas.

d) La cuarta noche y su albada, que no se ubica en un lugar concreto, como las anteriores, es o se presenta como un movimiento de atracción y repulsión a un tiempo. Así dirá la figura de la Muerte:

- " "Ya no me ves hermosa en la luz griega." A lo que el poeta contesta:

- Nunca lo fuiste; yo no te busqué/ por hermosura..." Y en la siguiente afirmmación, la muerte que es su "compañera", parte de su vida.

- "Me encontraste/ cuando eras casi niño, y desde entonces / siempre he estado contigo."

Este diálogo interior, que el poeta hace visible, acaba con una aceptación de la muerte, como compañera del viaje de la vida, pero solicitándole que su llegada, no sea traumática o consciente:

- "En medio de mi noche / envuélveme en el manto de la tuya,/ y sabré que por fin no duermo solo."

\subsection{Temática del libro}

La desolación y rechazo hacia la idea de la muerte es el tema principal del libro.

La temática, que nos resulta familiar en la obra del poeta, ya desde Dibujo de la muerte, (1967) (pues resulta una constante, en su obra de conjunto, el tratar temas que en cierta manera obsesionan al autor), es ahora tratada desde una dimensión si cabe más intimista, interiorizada, a la que ha revestido de dramatismo, al exteriorizar el diálogo interior, mediante una expresión dialogada.

El tema resulta una proyección autorreferencial de un sentimiento personal. Es el resultado de un largo proceso reflexivo en soledad, culmen de una experiencia no momentánea, sino resumen de toda una vida. Una reflexión que busca los espacios del pasado, que resumen y reúnen valores culturales, el tiempo de la memoria, el refugio de la noche; el silencio que lleva al conocimiento.

Lugar común en la literatura de todos los tiempos, el tema de la muerte, es mostrado en este poema como una lucha entre dos elementos, muerte-instinto de vida. Está tratado desde un existencialismo nihilista, en el que el protagonista, a pesar de buscar explicación, incluso "utilidad" a la muerte, no puede tener seguridades, tan solo el espejismo de eternidad de la memoria de los otros, o de más conocimiento, que no obtendrá, pues la misión de la muerte es dañar.

En el conjunto de la obra de Carnero, como señalábamos, no es este el único libro donde se trata este tema, pues es abordado ya en su primer libro, Dibujo de la muerte (1967), donde la belleza y aparente eternidad de los sepulcros y estatuas no pueden ocultar la realidad, no son sustitutivos de ella. También en su anterior libro, Fuente de Médicis (2006), el poeta dialoga con una estatua de Galatea, en un jardín parisino, en el que la muerte se hacía omnipresente como tal y en sus formas de ruina o de fracaso en la vida o en la escritura. Tras este libro, ambientado en la ciudad de París, aparece Cuatro noches romanas (2009) como continuación de 
esta dramatización. Ahora es otra ciudad, la de Roma. El espacio toma así verdadero valor simbólico, y hasta cierto punto exótico.

Configurando el tema general, aparecen otros temas, lugares comunes en la literatura. En primer lugar aparece el tema de el Tempus fugit, la fugacidad de la vida, contemplada en un amanecer o al comparar toda aquella arquitectura del pasado:

"Si, pero el tiempo vuela

Sobre la fluidez de su corriente...(20)

“El crepúsculo existe

unos pocos minutos: sus colores

son solo una ilusion que nos tienta en el aire" (34)

"el tiempo y la muerte nunca alcanzan su victoria"

- ¿Y no recuerdas tú dónde veias

oro con resplandor de eternidad?

-Sí, pero solo era

Brillo falaz de eternidad de oro." (56)

El tiempo y su amenaza es visto como el campo de las flores de la muerte.

Muy ligado al anterior aparece el tema del ubi sunt?, que se muestra en el poema a partir de la evocación de los tiempos pasados, del esplendor y triunfo de la juventud y el amor, la riqueza, el poder...

Era un jardín de amor

como lo fueron todos, el que hubiera

invenado el capricho de un dios joven,

con estanques redondos donde se reflejaba

la luz de las antorchas y ondeaba la seda.

Toda la belleza en un perfecto acorde:

la de los cuerpos jóvenes y piedras preciosas,

los metales, las telas, la música y los astros...(28).

Aunque sabe que aún no ha llegado su hora, se atreve a pedir a este personaje, a "la muerte", por su capacidad aniquiladora, que borre sus recuerdos, que le resultan dolorosos:

...Sé que no te merezco

todavía; te pido

solo una señal:Ilueve

sobre todas las folres, y deshójalas.

Arrastra mis recuerdos, que son manchas de sangre. (22).

Pero, por otra parte, la memoria le da conciencia de ser, y es "esa presencia" la que le pide que no mire atrás, es decir, no volver al pasado, pues, como él, otros buscaron la conciencia de ser: con ello nos muestra otro tema, el del hedonismo o la evitación del dolor.

5 Para este trabajo seguimos el libro de Guillermo Carnero (2009) Cuatro noches romanas, Barcelona, Crítica. 


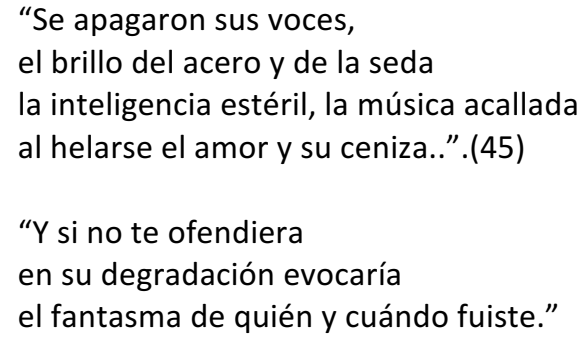

El poeta se muestra anhelante de un deseo de eternidad, que le pide a esta extraña presencia. Esta le ofrece, como una especie de sucedáneo, el refugio del recuerdo eterno de las tumbas, hechas de nobles materiales, y esculturas que buscan eternizar la figura o el recuerdo de alguien, como las que ambos contemplan en el Cementerio Acatólico, lugar de descanso de otros poetas, nobles, etc

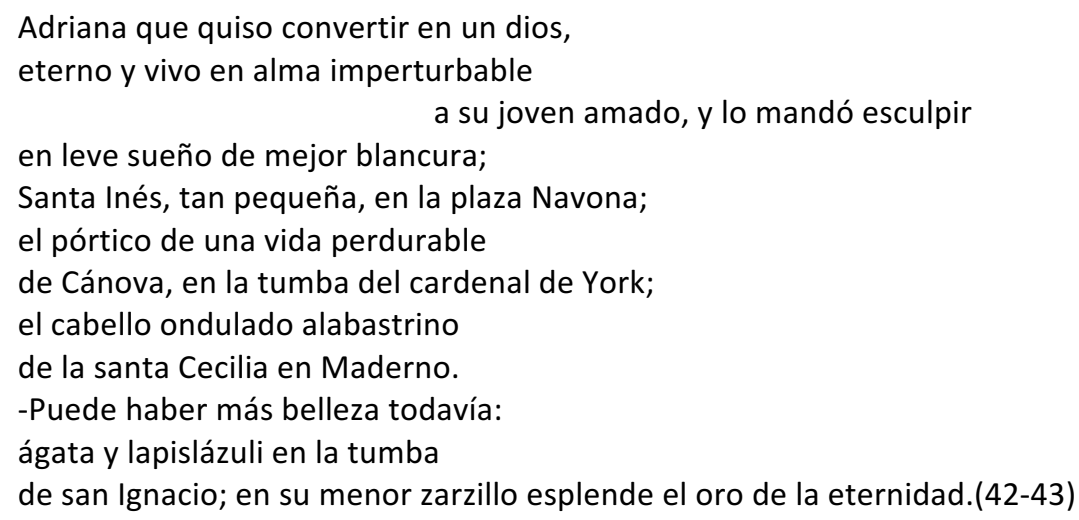

También es un tema recurrente el deseo de poseer la belleza, esta belleza que aparece eterna "la belleza de las tumbas", pero que no puede sustituir a la realidad, como así expresaba el poeta en su primer libro Dibujo de la muerte (1967), o estar en el espejo de los otros, en su memoria, donde construímos también nuestra identidad, aunque borrosa.

Sabes que existe un oro más precioso

Que el de las tumbas.

-sí; la doble fila

De espejos deformantes de la memoria ajena,

Si hubiera de cruzarla

en una urna que no habré elegido.

Y además, aparece en este diálogo la idea de la imposibilidad de ser salvados por la belleza o el amor, porque también ambos se degradan:

¿Por qué hace daño la belleza, y duele

en vez de consolar?

-Porque podéis

amarla, poseerla, destruírla,

pero no ser en ella, ni salvarla

de la degradación y la rüina". (29).

Unido al deseo de la belleza y la eternidad, aparece un tercer elemento, el deseo de conocimiento, (Él, que se siente "mendigo de eternidad y conocimiento") en especial el conocimiento poético. Así, dirá: 
"-Desde siempre me ha importado

Saber si en el desierto inabarcable

de la esterilidad de la palabra

hay un punto en que puedan dos miradas

encontrarse y decirse: somos una". (32)

El poeta declara en estos versos que busca un lenguaje que sepa comunicar con la palabra un sentimiento comprehensible también para otros, dentro de esa "polisemia finita" de la palabra poética. Para Carnero y otros poetas novísimos, hay cierta desilusión en la palabra poética, desconfianza en su autosuficiencia, por ello se justifica la necesidad de introducción de elementos extrapoético, o metaliterarios al poema.

En esos ofrecimientos y rechazos, el protagonista va depurando sus sentimientos, aceptando la muerte, que solo le ofrece, finalmente, incertidumbre, duda y la constatación de la nada final, sin tener siquiera el consuelo de la memoria prometida.

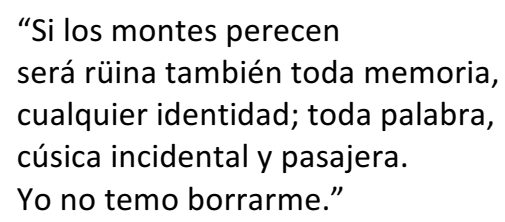

A lo largo del poema se desarrolla un sentimiento antitético con respecto a la muerte, pues es a la vez buscada y rechazada, la desea por su necesidad de olvidar y por "no sentirse solo", haciendo visible, al final, una idea un tanto "macabra":

\section{En medio de mi noche}

envuélveme en el manto de la tuya

y sabré que no he dormido solo.

La nada, como única salida final, será la idea con la que el poeta concluye el libro, a partir de un existencialismo nihilista, agnóstico, sin apoyos en seguridades religiosas. Además, es imposible salvarnos a través de engaños de amor y de belleza, pues la muerte es el engaño verdadero.

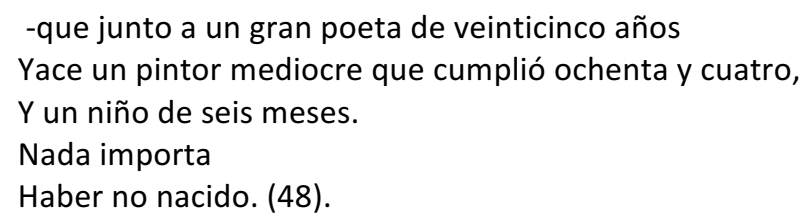

Por tanto ante el tema angustiador de la muerte, (que no puede expresar del todo esta angustia por la propia esterilidad de la palabra) y a partir de las preguntas que le hace al personaje, especialmente al final, el poeta va analizando a lo largo del poema sus inseguridades y sus miedos; buscará refugios en el conocimiento, la belleza, el deseo de eternidad, aun sabiendo, y a partir de una mirada al pasado, que todo es reducido por la muerte a la nada. 


\subsection{Recursos estilísticos}

\section{El verso}

En cuanto a la forma, Carnero prefiere para sus poemas la libertad versificadora, el verolibrismo, sin someter al verso a la monotonía de la estrofa, aunque sí es apreciable que use alguna vez la rima, sobre todo la consonante. El poema está compuesto por una larga serie de versos estructurados en cuatro partes, que se corresponden con los cuatro encuentros con ese personaje imaginario, personificado, que representa la muerte. Los versos, de metro irregular, suelen tener entre diez y catorce sílabas, también los hay de menos, de siete, pero son escasos, colocados al principio de cada parlamento de uno u otro personaje. Responde, pensamos, a un deseo de marcar los momentos de tensión del discurso dramático o conversacional, con estos versos de arte menor, o de crear ritmo, romper la monotonía de las reflexiones más largas; en ocasiones, son una llamada, o interpelación, entre ambos personajes, con formas verbales en imperativo: "Imagina, vete y olvida", "¿recuerdas?", o también presentan el contenido del siguiente parlamento: "Era un jardín de amor.", estamos en una hibridación de géneros, entre la poesia de experiencia emocional y la narratividad al introducir una forma de ensayo y reflexión en el poema.

\section{El léxico culturalista y barroquismo expresivo.}

La poesía de Carnero está caracterizada por un léxico intimista que incide en el aspecto visual, en la descripción de la escena. Por un lado aperecería el léxico que pertenece al campo semántico de la muerte, y sus atributos, lo decrépito del mundo. Cualidades que recalan, tradicionalmente, en lo pesimista, lo negativo, la nocturnidad, lo oscuro, lugares del olvido, del silencio, del abandono: tumbas, cementerios, casas o jardines en ruinas...es la destrucción de la vida. Palabras como olvido, ausencia, dolor amordazado, dañina, taimada, manchas de sangre, aguas pútridas del Tiber, destrucción, fatalidad, aridez, desesperación mendigo, rüina, estéril, indiferencia, rencor, sepulcros, esqueletos, mártir...etc. nos remiten a un léxico de tonalidades negativas. Y frente a este, un léxico perteciente a las numerosas citas culturalistas de otros poetas, o textos poéticos, (Jhon Donn, Leopardi, Byron) o referidos al mundo del arte o del pasado, que viene sugerido, muchas veces, por las diferentes ruinas de los espacios recorridos en la noche romana. Destacan las referencias a espacios arquitectónicos de la ciudad, espacios cerrados, jardines, villas cementerios, y una plaza, así mismo referencias del arte. Así, lugares como Villa Altobrandini, Acqua Paola, Plaza, San Lorenzo in Lucina, Alejandro séptimo, Cornelio Gala, Pórtico... o nombres de materiales del arte, piedras preciosas, como ámbar transparente, lapislázuli, oro, marmol, alabastrino... etc. evocan una belleza del pasado.Un trabajo de intertextualidad que el poeta realiza como una forma de hacer del poema un espacio, o universo, abierto significativamente.

Este barroquismo visual y cultural no se acompaña por una sonoridad externa sino que todo transcurre en el silencio de la noche, roto por el 
diálogo de ambos personajes. La preocupación por la muerte, y horror vacui, que se genera en su interior, y en la construcción del poema, se ve reflejado en los recursos léxicos y expresivos, nos ofrecen un poema caracterizado por una densidad conceptual y expresiva.

\section{Narratividad y reflexión en el verso}

Todas estas evocaciones intertextuales, junto a la propia condensación emocional del texto, están articulados a partir de un discurso reflexivo, cuya huella deja en los continuos razonamientos filosóficos, meditativos, o metapoéticos, del yo lírico que se manifiesta en el poema como un yo reconocible en el poeta, como ser histórico-cultural. Una reflexión sobre su propia literatura, no sobre la literatura en general. Para el poeta es natural unir pensamiento y emoción. La narratividad, o discursividad, esta presente en la exposición de ideas, pensamientos, hechos, recuerdos en el poema, visto como un relato. Sintácticamente aparecen los paralelismos, bimembraciones, sustantivación, verbos pronominales, de lengua, pensamiento.. que aportan lentitud al ritmo de lectura. También destaca la abundante adjetivación con efecto intensificador de los aspectos negativos. Este discurso con tintes negativos del personaje de la muerte, se muestra además por la abundancia de frases sentenciosas y por la definición de conceptos. Veamos aquí unos versos, que parecen parafrasear a Bécquer, en los que utiliza una estructura paralelística.

"La música se aleja como un cendal bordado...

La ola empieza siendo un leve rizo...

El verde de las hojas deriva en amarillo...

El ave pasa rauda y nunca vuelve. (30).

O estos otros en los que aparecen bimembraciones, que aportan lentitud, a la vez que matización, al estilo de Garcilaso de la Vega

Sí pero el tiempo vuela

sobre la fluidez de su corriente.

frecuente y encendida en luz veloz;

la remansa y la enturbia, dejando un lado tenso...(20).

Aparecen, así mismo, versos que contienen sentencias, conceptos, en los que tiene cabida el símil o la metáfora:

Un día me dijiste: tu peor enemigo

es la memoria; aprende de los pájaros...(41).

"La aridez es el reino de la paz

y la misericordia solo arena."

En cuanto a las verbos, como decíamos, pertenecen al ámbito del razonamiento: pensar, decir, hablar, imaginar, querer, olvidar, recordar, preguntar, suponer, saber...etc. además del predominio de las oraciones imperativas e interrogativas, reflejo de un tipo de texto dialogado, que indica el interior del poeta: "Olvídate, no mires atrás, vete y olvida", "pregunta/pero evítame quejas y gemidos." "¿No recuerdas a aquel a quien 
dictaste/ que es tumba de sí el propio Aventino?" Lo cual ofrece a la lectura cambios de ritmo, emotividad, un registro más coloquial, y, a la vez, un estado interior, en desasosiego por saber, del poeta.

3.4. La tensión "dialéctica" del diálogo, se dibuja a partir de ciertos recursos semánticos: Ironía, paradoja, contrastes, antítesis, metáfora, simbolismo.

El diálogo, entre el poeta y el personaje de la muerte, se desarrolla envuelto en una tensión dialéctica, una "esgrima verbal" que lleva a ambos a una posición de claro enfrentamiento, entre la impasividad e impiedad de uno frente a la desazón y turbulenta vivencia del poeta.

Los recursos semánticos que el poeta utiliza responden al deseo de mostrar de manera permanente la antitética relación vida-muerte. Nada es visto en su plenitud, sino con algún atributo o signo de su destrucción, como vemos en estos elementos de curiosa adjetivación, negativa: antiguo poder, tiempo insondable, aguas pútridas, luz negra, piedra anochecida, lugar oscuro, fuente muda, escalones rotos, muros raídos, donde predominan los colores oscurecidos por la noche, que han perdido intensidad: azul tibio, rojo ceniciento, del verde de las hojas al amarillo y al ocre. $\mathrm{O}$ indicativos de fugacidad: leve rizo, fugaz espuma, breve y débil vida de la rosa.

Siguiendo este camino de enfrentamiento, y mordacidad, en el poema nos encontramos con el uso de la ironía, el contraste, la paradoja, a la par que otros recursos más elaborados, como son el simbolismo de ciertos elementos (la luz, animales como la paloma, el lince, la fuente, el jardín), las metáforas, la alegoría, significados que se construyen a través de una continua referencia al culturalismo y la metapoesía.

La ironía, unida a la mordacidad, desempeña, en el conjunto de la significación del poema, la manifestación de esa desconfianza y desdén sobre todo de ambos personajes. Así, el poema comienza como un encuentro de dos viejos "amigos", pero que resulta irónico, conociendo el desarrollo posterior. "Después de tantos años escribiéndome/ hoy has venido a verme" $\mathrm{Y}$ del mismo modo, el poeta expresa que no desea la muerte de esta manera: "Sé que no te merezco todavía..." También en el jardín de Villa Aldobrandini dirá: "Debes/ de sentirte humillada si fuiste alguna vez/ hermosa y deseable." Y en otro ejemplo, en la última parte, la figura de la muerte le ofrece una especie de paraíso si la elige en ese momento, aunque también le dice que le queda poco tiempo:

"Compartiremos

Un glorioso vergel interminable

de amor y de silencio, que fluyera

con gorgoteo plácido de fuente." (54).

La creación de un lenguaje contradictorio, en apariencia, y paradógico, aparece en función de que el poeta ha cambiado los valores de las cosas, porque las ve con la óptica de la muerte, así la luz, caracterizada por la claridad, la blancura, será ahora : luz negra, luz ciega...y así podemos ver más ejemplos como: "me cegaba la luz", "llueve sobre todas las flores, y deshójalas, esplendor inútil, lluvia de arena", etc. 
Otro recurso importante en la poesía de Guillermo Carnero ha sido la creación de personajes y máscaras para representar al yo poético, o desdoblarlo, creando una voz poética polifónica. En este caso ha elegido la personificación de la muerte, y lo ha hecho dotándola en su descripción, física, y hasta moral, de las características y de los atributos que la iconografía popular, literaria, pictórica, le ha dado en la tradición, además la ha dotado de la palabra, a través de la cual se convierte en un personaje de contradicción para el poeta.

La actuación de la muerte, en su perenne gobierno, ha sido la de sustraer vida, amor, sensibilidad, sin ningún tipo de misericordia, causante de todo lo negativo que le ocurre al hombre; amada con desespeación pero fría, que no ama a nadie, dañina y taimada, cuyo mayor engaño es ella misma. En el poema aparece cual una dama acudiendo a una cita amorosa, y es ella la que en una especie de viaje a los infiernos de Dante, muestre al poeta el pasado y el presente; un pasado en el que era más temida, hasta vista con hermosura, con un reinado más visible, pero hoy está oculta en los cementerios, nadie la busca a no ser los desesperados y otros tipos como mendigos, o drogadictos; sin embargo el poeta se siente mendigo de conocimiento y eternidad, en cambio ella le aconseja ser como el lince, no hay que pretender mirar muy lejos, y ofrece al poeta, de manera irónica, una ilusoria serenidad, paz y belleza, o la sabiduría del olvido: aconseja no recordar nuestro pasado para no sufrir, ser como simples pájaros, palomas, no conscientes de ese dolor.

Mención especial merece el simbolismo del espacio en Cuatro noches romanas. En la poesía de Guillermo Carnero el espacio posee un simbolismo que él mismo ha explicitado en sus poéticas. Así dirá:

El ser humano se encuentra entre dos grandes espacios: el espacio natural y el espacio arquitectónico; el segundo es una intervención en el primero con el propósito de hacerlo menos agresivo, y por eso la Arquitectura tiene su más remoto origen en lo que el mundo natural ofrece protección y cobijo al hombre indefenso: el árbol y la caverna. La dualidad entre naturalleza y Arquitectura se halla instalada en el subconsciente y determina dos actitudes instintivas en su oposición. (2008:120)

Y continúa diciendo que optar por la naturaleza es optar por el vitalismo, mientras que elegir lo arquitectónico es un deseo de protección o un sentimiento de soledad. El poeta es consciente de que siente predilección por lo arquitectónico por los espacios cerrados, incluso en ruinas. "Estos espacios suelen simbolizar soledad, aislamiento, incomunicación, también la inutilidad y fracaso de refugio en la belleza del arte." (2008:123). En cuanto a los espacios abiertos como la plaza, esta representaría la soledad también y disolución del yo, sobre todo cuando está vacía a ciertas horas. Estos espacios están llenos de fuentes, estatuas, en especial de cuerpos humanos femeninos que adornan jardines o cementerios, y simbolizan amar lo efímero del arte, el amor perdido, aportan un clima espiritual, ocultan la ruina de la muerte. En Cuatro noches romanas, el poeta sigue utilizando los mismos símbolos, presentando el espacio exterior como correlato del interior. En primer lugar la propia 
ciudad de Roma, que ya desde el título, adquiere valores de eternidad para el poeta, valores de la ciudad total, donde conviven pasado y presente, como los espacios que recorre en la noche, de pasado glorioso, y que también para él simboliza la sincronización de su pasado y su presente. También fueron, en ese sentido, simbólicas las ciudades de Londres en el libro Jardín inglés o París en La fuente de Médicis. Así de Roma dirá:

"Qué odio a esta ciudad santa y mugrienta

Escarabajo que empuja su pelota

De éxtasis, bodas místicas y transverberaciones,

De momias enjoyadas y mártires desnudas

Y efebos desollados entre el olor a incienso..." (33).

Estos espacios del poema tienen una localización precisa y un sombolismo cultural y personal para el poeta:

Parte I. La plaza de Campo de'Fiori (campo de las flores), es una plaza de Roma que se encuentra en el rione Parione. Hasta el siglo XV la plaza no existía y en su lugar había un prado florido, del cual deriva su nombre. ${ }^{6}$ Sus "Fiori" son para el poeta manchas de sangre, y el campo de flores, el campo de la muerte.

Campo de 'Fiori sirve de presentación de los atributos de la muerte, el lugar de las ejecuciones un lugar sin piedad donde "reinaba" la muerte.

"Te has hecho encontradiza porque sabes

que tu antiguo poder está olvidado.

nadie te recuerda."

"Aunque careces de misericordia

te envuelve sueño altivo

de recelos de reina destronada." (15)

Para el poeta la devastación de la muerte no está acabada, pues el espacio, como el de esta plaza, no desaparece, cuando todo acaba, como ocurre con el tiempo.

“¿Por qué persiste en ser inmortal el espacio, indiferente al tiempo?

Cuando acaba

la representació, el espacio

debiera perecer. Al disiparse

las últimas palabras con ellas descendiera

perpétuo infranqueable telón de oscuridad

sobre la ausencia y la oquedad del tiempo." (16)

\footnotetext{
6 En el año 1456 el papa Calixto III hace pavimentar la zona como parte del proyecto más amplio. Esta remodelación contemplaba la construcción de importantes edificios, entre ellos el de la familia Orsini. Por este motivo la plaza se hace un lugar de paso obligatorio para las personalidades más relevantes tales como embajadores y cardenales. Esto aportó un cierto bienestar a la zona, surgieron en su entorno muchos locales, albergues y talleres de artesanos. También fue sede de un floreciente comercio de caballos. La plaza se convierte en un centro de actividades culturales y comerciales. En el texto aparece mencionada esta plaza como lugar señalado por la muerte. En Campo déFiori tenían lugar ejecuciones públicas. En el año 1600, el 17 de febrero, aquí fue quemado vivo Giordano Bruno, en cuyo recuerdo se construyó un monumento erigido en la misma plaza en el año 1889, obra de Ettore Ferrari.
} 
El espacio no desaparece, porque la misión de la muerte es dañar, pues como ella dice: "...así lo que se apaga/con mayor lentitud sufre la ausencia/ de lo que ya no existe..." (19) El espacio, simbolizado en las losas de la plaza, están "bañadas en dolor amordazado." Para la muerte, su campo de flores en en realidad el tiempo insondable. Además la vida es así vista como una representación, un engaño.

Parte II. Jardín de Villa Aldobrandini. En las laderas de Roma, cerca de Frascatise levantó entre los siglos XVI y XVII Villa Aldobrandini, por el cardenal Pietro Aldobrandini, siguiendo los deseos de su tío, el papa Climente VIII, como un lugar de descanso estival. Pertenecía a una familia florentina enemistada con los Médicis. Anteriormente había sido una villa más modesta, Villa Contugi, levantada sobre una antigua villa romana, Lucullus. Un palacio con fuentes y sus juegos de agua y jardines que ascendían por las laderas, casi silvestres, fueron diseñados Giacomo de la Porta y Carlo Maderno, un conjunto considerado uno de los primeros modelos de Villa del barroco romano. Lleno de esculturas, mosaicos columnas...reflejaba las inquietudes intelectuales del papa y su sobrino, amantes de la antigüedad romana y protectores de artistas. Los jardines, mencionados en el libro de Carnero, eran otra maravilla: colocados en parterres, con bosquecillos hacia las laderas simulando una vegetación silvestre, con plataneras de sombra, que aún existen hoy, con fuentes. Sus referencias tienen relación con el tema del recuerdo del pasado, del ubi sunt?, al recordar las fastuosas fiestas, en esta villa romana donde se promocionaba la cultura y la literatura por sus mecenas. Simboliza para el poeta el deseo de conocimiento y eternidad, de comunicación, a través de la belleza de la palabra poética. Una palabra en la que coincidan dos miradas, la del escritor y la de lector. Además el jardín simboliza para el poeta la salvación de la naturaleza: sus muros son el cuerpo protector, un jardín de amor, donde se hablaba de literatura:

\footnotetext{
"Porque naturaleza solo consigue serlo

si se salva de sí misma en arte.

Entre los muros de un jardín concluso

donde puede medrar toda belleza"(29)
}

Aunque, ahora le atraiga al poeta esos escalones rotos y sus roídos muros, la fuente muda, cuya taza cubre un amasijo de raíces muertas, estos elementos le sirven para preguntar por el pasado, y quiere satisfacer su curiosidad preguntando a la muerte. Sin embargo, y haciendo un paralelismo con la fuente cubierta por ramas, sin vida, ella dirá: "vete y olvida / tanto amasijo de preguntas muertas", (35) pues como ya había dicho más arriba "La ignorancia de lo que fuimos da serenidad".

Parte III. Cementerio acatólico, o también llamado de los poetas. Situado en la vía Caio Cestio, se encuentra el encantador jardin arbolado donde yacen las tumbas de algunos de los alemanes e ingleses más famosos del siglo XVIII. Antes de llegar, en la misma calle sorprende la visión de la extraña pirámide, tipo egipcia, que mandó construir el pretor romano Cayo Cestio en el año 12 a. C., cerca de la porta de san Paolo, para 
que le sirviera de mausoleo. El cementerio protestante funciona como tal desde 1738 para los no católicos. Entre sus intrincados senderos se encuentra la tumba de los famosos poetas románticos Jhon Keats, o Percy Bisse Shelley... muertos muy jóvenes y de vidas novelescas.

La elección del cementerio de los poetas, el favorito de los amantes de la literatura inglesa, tiene también una significación especial. En dicho cementerio están los poetas y escritores que han influido en el poeta, muertos, como dice el poema, en la luz del medio día, un lugar donde la muerte parece hasta bella. Estos poetas del primer romanticismo, rebelde, enfrentaron de forma distinta el tema de la muerte, para ellos suponía la salvación, una puerta para unirse al espíritu panteista de la naturaleza. De hecho comienza esta parte del poema con una cita de Sheley, de su poema Adonais, estrofa 33: "Lo que la muerte puede unir, que no lo separe la vida"

También hará referencia a la tumba de Keats, y de su muerte:

\footnotetext{
“Esta simple lápida

En su serenidad de luz a medio día

Fue designio de un hombre atormentado

En muerte nocturna"
}

Este cementerio es símbolo de la belleza que puede haber en la muerte, como así se muestra por la profusión de referencias a las estatuas que lo pueblan: amorcillos, muchachas griegas, otras de santos, pues solo la estatua puede conservar lo efímero, como pueda ser un cabello ondulado, y resaltando a su vez la espiritualidad del espacio. Además señala del papel igualador de la muerte, pues en él reposan niños, jóvenes, ancianos, artistas en general, que como él buscaron identidad de ser.

Parte IV. Noche cuarta y Albada. En esta última noche el espacio se ha despojado de toda referencia arquitectónica, solo hay alusiones, y ahora se encuentra en el espacio de su cama, como si todo lo anterior fuese un sueño, el a solas con la muerte, a punto de amanecer, de llegar la luz, lugar donde no puede ser vista. Es el punto final de una serie de experiencias y extraña relación con la muerte, expresado como un cierto coqueteo morboso, aplazando la cita, prometiéndole, ella, ayuda "acudiré a tu lado si me lo pides", algo que rechaza el poeta, aunque acaba resignándose al destino, y ve ese momento final como un acto de compañía, así dirá el poeta: "y sabré que por fin no duermo solo".

Las referencias culturalistas y metapoéticas aparecen muy integradas en el espacio y poseen una función ciertamente simbólica, no para reforzar la erudición, que la hay, o el discurso referencialista culto. No son ajenas a la sentimentalidad del poema. Aquí están expresando una parcela importante del sentimiento, que dibuja la imagen de la experiencia íntima del yo lírico. Como ha señalado el propio Carnero, "La presencia de un sistema de referencias artísticas en un corpus de poesía ha de ser considerada como un factor de literariedad y por ello de expresióndel yo a través del arte resulta de la verdad y de la autenticidad intelectual y emocional en aquel para quien el arte ha sido un elemento irrenunciable y primordial de conocimiento del mundo" (Carnero, 2008: 119). Por tanto es 
una necesidad a la vez que un homenaje del poeta hacia el arte, él que siempre se ha sentido atraído, "desde que he tenido uso de razón he sentido la llamada del arte" "por su silencio, su belleza y armonía", (119).

Las referencias culturalistas se concretan en la inclusión en el poema de versos de poetas que también tuvieron una especial relación con la muerte, y la reflejaron en su obra, en especial aquellos que poseían una cosmovisión romántica de la existencia o bien por su carácter metafísico o filosófico. En primer lugar y abriendo el libro aparece un verso del poeta inglés John Donne, de su elegía XII: "His Parting From Her " ("Al separarme de ella") : Environ me with darkness, whilst I write"; "(rodéame de tinieblas ahora cuando escribo".)

Lo que le interesa resaltar a Carnero con esta cita es el deseo de que le rodee la noche mientras escribe, es decir, la noche será la que marcará las relaciones y experiencias de su poema. La noche como símbolo de conocimiento interior y aislante, con su tiniebla, del mundo visible, para introducirlo en el misterioso. A la vez que, de esa forma, enmascara su soledad, su "infierno". Como lo es, en esta elegía, el abandono de la amada. Jhon Donne escribió pocas elegías en las que la muerte se mencionase directamente, sin embargo es algo que le aterrorizaba. Su presencia solía ir disfrazada con los lamentos de la separación. Al igual que Donne, Carnero escribirá aquí una poesía metafísica.

Aparece luego, al comienzo de la primera parte, un verso del poeta $\mathrm{F}$. Hölderlin, de su poema Griechland ${ }^{7}$, en el que muestra una atracción especial por Grecia: por lo misterioso, lo sensual y lo vital. : "Mein Herz gehört den Toten an" (Mi corazón es ya de los muertos). Es un verso que evoca y alude al estado de tristeza que envuelve al poeta. Hay paralelismo y afinidad entre cierta concepción del mundo clásico en el poeta alemán y Carnero. Hölderlin se inserta en la tradición, incipiente, de la literatura que no considera el mito como simple alegoría, metáfora o historieta, sino como órgano adicional del hombre para captar o interpretar la realidad circundante. En ambos poetas la contemplación de ese mundo perdido, de esas formas artísticas representadoras del mismo, les produce una especie de ausencia. Carnero integra a la fibra sensible el culturalismo y Hölderlin es "el profeta de los hombres que se han quedado sin dioses".

Al inicio de la segunda parte hay una cita de un verso de Leopardi, el gran poeta lírico de Italia, romántico, entresacado de las cartas "Al conte Carlo Pepoli: "Ogni beltate o di natura o d'arte fatta inanime e muta".

La siguiente cita procede del poeta inglés Shelley, de la estrofa 53 de la elegía Adonais: "No more let life divide what death can join together" (Lo que la muerte puede unir, que no lo separe la vida"), inspirada en la muerte de Keats (1821), el poeta llora la temprana muerte de su amigo, expresa todo su dolor e invita a la musa Urania invitándola también a llorar con él. Acaba esta elegía de manera más serena transformándose en un himno de alegría pues Adonais no ha muerto, está entre inmortales. Aquí la muerte es vista como liberadora por medio de la cual el alma del hombre puede 
unirse al espíritu del universo. Carnero ha elegido este autor y esta elegía por la idea de la inmortalidad del alma, en la figura de Adonais, mito griego de la renovación de la primavera, para hablarnos de eternidad y de belleza en esta tercera noche, una inmortalidad a través del arte.

Al inicio de la cuarta noche hay una cita de Chateaubriand, de Mémoires d'outre-tombe, XLIV, I. "Cette main me fait signe d'abréger" (Esta mano me hace signo de abreviar). Memorias de ultratumba, escritas en prosa poética, es una autobiografía, que comenzó a escribirse en 1809 y se acaba en 1841. Publicado en 12 volúmenes, entre 1849-1850. Este autor, idolo de la joven escuela de románticos francesa, nos muestra, en esta melancólica obra, su yo interior, al tiempo que los acontecimientos históricos y políiticos. Carnero parece indicarnos sutilmente que su libro es como unas memorias, que tienen algo de autobiografía, de su mundo interior y que el final está llegando y es necesario "abreviar", pues la muerte le dice: t"e queda poco tiempo"; también el tíitulo del libro "Memorias..." alude al "más allá", abriendo una puerta a lo irracional y a la ficción.

Como podemos apreciar, las referencias a otros poetas quedan justificadas para un autor que pone en su poesía, a demás de la emoción, el hecho cultural y reflexivo, algo connatural en su experiencia. En ellos busca un concepto de muerte que se abre a la idea de eternidad a partir de la belleza que ciertas culturas, como la griega, le han imprimido.

Mención especial merecería recordar la rica tradición literaria en torno a este tema, de la que se ha nutrido y a la que se ha unido el poeta, desde Las danzas de la muerte, Los romances, como el de El enamorado y la muerte, los cancioneros, los plantos como el de hizo Juan Ruiz por la muerte de la Trotaconventos....El sueño de la Muerte, de Quevedo...etc pero que quedan fuera de nuestro propósito por no alargarnos.

\section{A modo de conclusión}

Cuatro noches romanas es, en cuanto al estilo, un ejemplo de la perfección a que ha llevado Carnero la técnica de la utilización del culturalismo y metapoesía en el poema, para llevarnos a un mundo rico en matices y referencias culturales, que hacen del texto una joya literaria, de brillo intelectual y agudeza creativa. Además, esta, la ha sabido encajar dentro de una tradición de la que se siente heredero. Todos y cada uno de los elementos de esta especie de representación dramatica, el escenario, a arquitectura o el paisaje, la ciudad, los parlamentos, la dialéctica discursiva, de búsqueda de respuestas entre la desesperación y la aceptación, han estado cincelados desde una óptica cultural, que embellece y codifica, que da forma al sentimiento, a la experiencia interiorizada. Es un poema que no deja indiferente, producto original, entre la alegoría y la verdad, para expresar un proceso, la soledad del hombre frente a la muerte.

Dentro de su trayectoria poética, en esta última etapa, y en concreto desde Verano Inglés, (1999), Guillermo Carnero había inaugurado una 
etapa de meditación y de interiorización existencial. En Cuatro noches romanas (2009) asistimos a una expresión poética que profundiza en esa elección por la filosofía y la reflexión metafísica, temáticas que recuperan la visión neobarroca y romántica de la muerte, de indagación en el yo, de reconstrucción del sujeto que siente un vacío en alguna parte de su ser. El ser humano se siente incompleto, en tanto que le falta la respuesta última, y ha de buscarla en su interior. En cada libro, como señala el propio autor, hay una relación problemática con la realidad, en este caso es la no aceptación de la muerte, como experiencia que da dolor, y justamente será a través de la palabra poética, mediante su enunciación, como puede construir el mundo y a sí mismo. No le sirven, por tanto, las soluciones tradicionales tendentes a ocultarla o recluir la muerte y su imagen en los espacios engañosos del arte o la memoria.

Guillermo Carnero, el poeta, ha mirado en los espejos de la cultura para descubrir la figura de la muerte, de los que ha tomado forma y voz y que no es sino una proyección de sí mismo, una mise en abîme de su angustia, que finalmente ha podido aceptar, o ese parece ser el mensaje último del libro, aunque, no desea ser consciente de su llegada.

\section{Bibliografía}

Alvar, Manuel (2000): "En el arrabal de la senectud" en Cauda. Leer para el recuerdo, pág. 44 y sig.)

CARNERo, Guillermo, (2009): Cuatro noches romanas, Tusquets, Barcelona.

_(2008): Poéticas y entrevistas, 1970-2007, Universidad de Alicante y Centro Cultural Generación de 1927, Málaga.

_(1979): Ensayo de una teoría de la visión (Poesía 1968.1979), (estudio preliminar de Carlos Bousoño), Hiperión, Madrid.

CASTELLET, José María (2006): Nueve novísimos poetas españoles, Península, Barcelona.

DIRSCHERL, Klaus (1994): “Del juego de máscaras al redescubrimiento de la subjetividad" -cap. La novísima lírica española- en Abriendo caminos la literatura española desde 1975 (281-291) Lumen, Buenos Aires.

García Montero, Luis (1993): “ La poesía de la experiencia”, Confesiones poéticas, Colección Maillot Amarillo, Diputación Provincial de Granada, Granada.

García PosAdA, M. ((1998): La nueva poesía española (1975-1992), Crítica, Barcelona.

Hölderlin, F. (2005): Poemas, col. Visor de poesía, Madrid.

JONGH ROSSELL, Elena de (1982) : Introducción al libro: Florilegium poesía española, Espasa- Calpe, Madrid.

Novalis (1995): Introducción a Himnos de la noche. Cánticos espirituales, Edición bilingüe. Traducción de Américo Ferrari. Pre-textos, Poesía, Valencia. 
SÁnCHeZ TORRE, Leopoldo (1993): La poesía en el espejo del poema (la práctica metapoética en la poesía española del siglo XX) U. Oviedo, Oviedo.

TALENS, Jenaro (2000): El sujeto vacío. Cultura y poesía en territorio Babel, Cátedra, Madrid.

VVAA, (1996): Paisaje, juego y multilingüismo (Actas del X Simposio de la Sociedad Española de Literatura General y Comparada), edición de de Darío Villanueva y Fernando Cabo, Universidad de Santiago de Compostela, Servicio de Publicaciones, Santiago de Compostela.

\section{Webgrafía}

http://www.elcultural.es/version_papel/LETRAS/25354/Cuatro_noches_romana $\mathrm{s}$

http://revistas.ucm.es/fll/11339527/artículos/CFIT0202110213A.PDF

http://books.google.es/books"lagrecofilia"

http://es.wikipedia.org/wiki/biografias 